\title{
Towards an Alternative Foundation for Managing Product Life-Cycles in Turbulent Environments
}

Lars Taxén and Daniel Svensson

\section{Linköping University Post Print}

Tweet

N.B.: When citing this work, cite the original article.

Original Publication:

Lars Taxén and Daniel Svensson, Towards an Alternative Foundation for Managing Product Life-Cycles in Turbulent Environments, 2005, International Journal of Project Management, (2), 1-2, 24-46.

http://dx.doi.org/10.1016/j.ijproman.2008.05.009

Copyright: Elsevier

http://www.elsevier.com/

Postprint available at: Linköping University Electronic Press

http://urn.kb.se/resolve?urn=urn:nbn:se:liu:diva-54019 


\title{
Towards an Alternative Foundation for Managing Product Life-Cycles in Turbulent Environments
}

\author{
Lars Taxén \\ Linköping University \\ Department of Computer and Information Science \\ SE - 58183 Linköping, Sweden \\ lars.taxen@telia.com \\ Daniel Svensson \\ Volvo Information Technology \\ Industrial Solutions \\ SE - 40508 Göteborg, Sweden \\ daniel.pg.svensson@volvo.com
}

\begin{abstract}
With the deregulation of the markets and the introduction of new technologies, the need to manage diversification, change and complexity in product development has become crucial. To cope with this situation an alternative foundation for PLM is needed in which organizational issues are considered alongside with more traditional technical ones. Such a major reorientation of PLM needs to be informed by a theoretical perspective which integrates social and technical issues into a coherent framework. In this paper we propose the Activity Domain Theory for this purpose. This theory has been used as a guide at the Ericsson telecommunication company in order to suggest an alternative foundation for PLM. Preliminary results are the enhancement of the organizational language with the construct of activity domains, a clean-up of fundamental categories in information management, a multi-domain product structure concept, an alternative business process model, an information system managing core information elements and a strategy towards balancing centralized and decentralized control.
\end{abstract}

\section{Introduction}

The deregulation of the telecommunication market and the emergence of new technologies during the 1990s have created an entirely new situation for companies developing products such as telecommunication systems. A long period of comparatively stable conditions has been succeeded by a turbulent period characterized by instability, uncertainty and an ever-increasing rate of change. The scope of this paper is the impacts of this turbulent situation on product life-cycle management (PLM). PLM concerns among other things the way in which products are structured, how the coordination of activities is carried out, what information systems (IS) are used to support the management and what rules apply to the management. In any particular organization, these components of PLM evolve over time into a management foundation which becomes more or less established as a natural and accepted way of managing product life-cycles.

The transition from the stable to the turbulent situation has brought to the surface a number of contradictions or tensions between the traditional management foundation and current needs. These contradictions are mainly due to the inadequacy of the traditional foundation to cope with diversification, change and complexity. Moreover, social issues such as the contextual dependencies of shared and commonly accepted beliefs, will have an increased influence [19]. For some time these contradictions can be handled by 'patches' in the traditional foundation, but eventually this foundation must be replaced by an alternative one.

The purpose of this paper is to discuss the application the Activity Domain Theory (ADT) as a guiding framework for building an alternative foundation for PLM. The ADT was suggested by Taxén as an informing framework for coordinating development projects for the $3^{\text {rd }}$ generation of mobile systems at Ericsson, a major worldwide provider of telecommunication systems [30], [31], [32]. The ADT puts, among other things, product structures, process models and ISs into a coherent framework where the focus is on how to achieve a shared meaning about these elements among the actors.

The paper is organized as follows: After an account for the research design we introduce the main approach of the paper which is to regard PLM from a coordination point of view. This enables us to relate PLM to the ADT. This is followed by an introduction of the ADT and how it is operationalized for PLM purposes. In the subsequent chapter we report on some results from applying the ADT in the Ericsson telecommunication company. A main result is that an elaborated conceptual foundation, based on the notion of activity domains, was established as a bridgehead in the company. Other results are suggestions of new multi-domain product structure, an alternative type of process model, an IS managing core information elements and a mechanism to 
balance between corporate central control and local autonomy. In the last chapters we discuss these results and draw some conclusions.

\section{$1.1 \quad$ Background}

During the stable period, the customers of telecommunication systems were mainly government owned operators with long-term, nationwide infrastructure investment plans. Telecommunication systems providers such as Ericsson, offered complete systems which were developed and manufactured in-house. The systems consisted of comparatively few technologies and evolved at a slow and steady pace. The management foundation during this period focused on the development and production functions and less on functions such as marketing and service. Since the entire life-cycle of the system was under the control of the same company, a comparatively homogeneous way of managing the life-cycle was established.

After the deregulation, many new operators have been established in the telecommunication area. This has led to an increased focus on company functions such as marketing and service. Another consequence is an increased instability of the market since the operators often have conflicting requirements which are frequently changed. Furthermore, the operators have currently invested heavily in licenses and networks for the new generation of mobile systems. At the time of the completion of this study the incomes have been less than expected which caused the market to more or less collapse during 2002. This had tremendous impacts on development plans and organizational structures. A number of cost-reduction initiatives were launched such as outsourcing of functions like production, supply and IT management. The number of employees were cut drastically. For example, at Ericsson the staff was reduced from 107,000 employees to less than 50,000 in a few years. As a result the company structure has changed from a fairly homogeneous all-in-one organization to the so-called extended enterprise, in which a number of heterogeneous organizations are collaborating to develop and produce the system.

The turbulence of the market occurred during a period of an ever-increasing complexity of the telecommunication systems themselves. As an example, a node in the $3^{\text {rd }}$ generation of mobile systems (the socalled Mobile Switching Centre node) is shown in Figure 1. During the development, several hundred contributions from development sites all over the world must be coordinated. Each white box, which is called a work package, signifies the development of a certain functionality. The arrows between the boxes indicate dependencies among the work packages, starting with the most basic task at the top of the figure. The thick arrows mark the content and date for a particular integration and verification of a number of packages. The 'bubbles' signify basic services in the node like registration of the location of the mobile phone, calling to the mobile phone, answering a mobile call, etc. In most cases the functionality is provided by software. The figure is called the 'anatomy' of the system since it illustrates the order in which the actual system 'comes alive', starting with the most basic functions at the top and progressing downwards. In short, the anatomy illustrates the integration steps of a large and globally distributed software development project where the number of source code lines may be of the order of millions. 


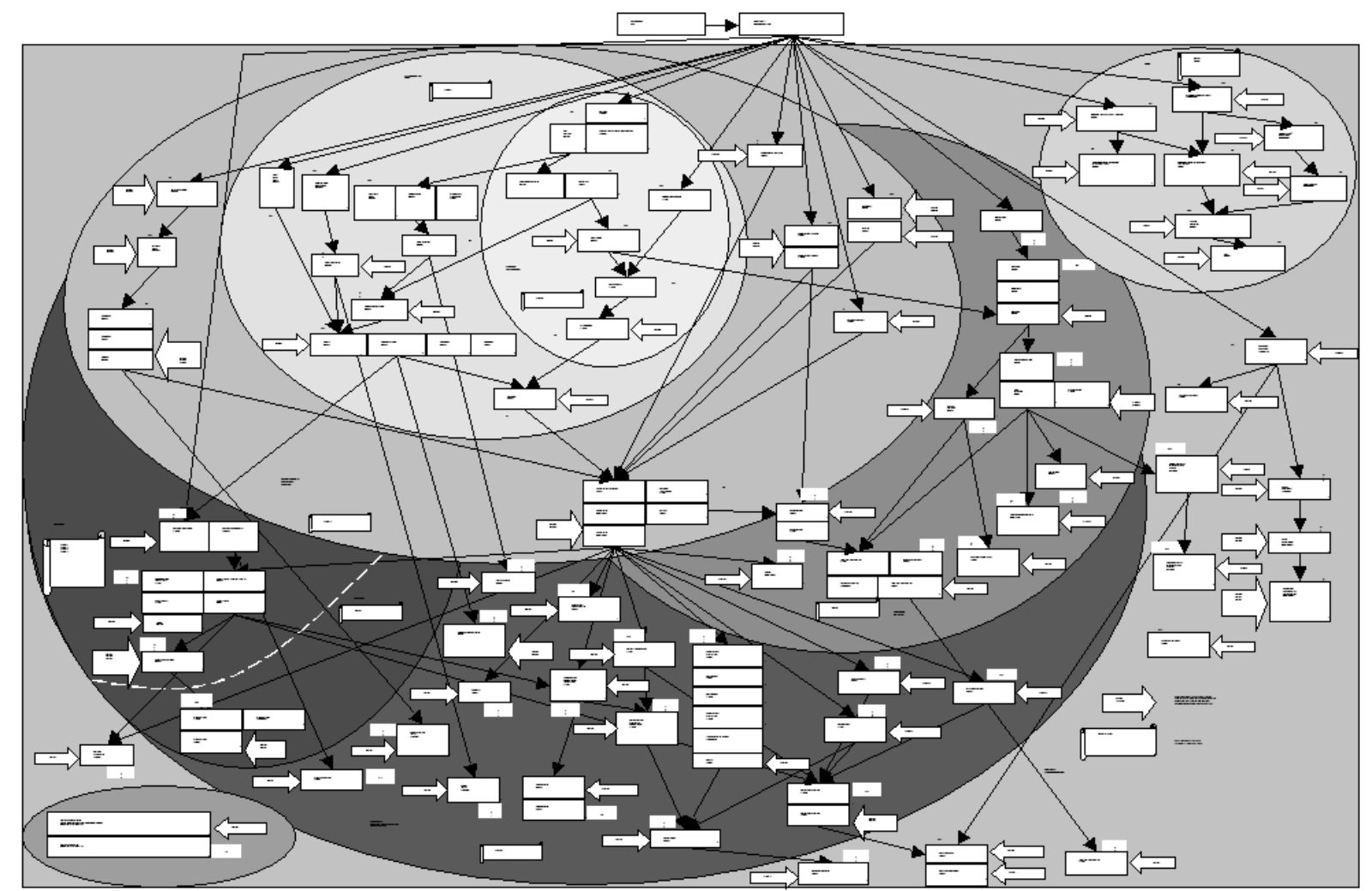

Figure 1. Dependencies between development tasks

The contradictions between the traditional management foundation and the needs caused by the transition to the turbulent situation have brought to the surface a number of concerns:

- Conceptual disarray: The fairly long stable period made it possible to evolve a consistent set of concepts in the management foundation. This set of concepts, which may be regarded as an organizational language, is to some extent unique for each organization and cannot easily be translated to outside contexts. The diversification means that the traditional language is inadequate for signifying activities in the new functions, both within the company and across to cooperating partners. The inability to solve this difficulty results in a conceptual disarray.

- Increased interdependencies: During the stable situation, the components of the management foundation were comparatively independent. Product structures, process models and ISs could be developed and maintained in relative isolation from each other since the rate of change was small. In the turbulent situation however, the interdependencies between these components are much higher. At Ericsson, the failure to realize this has caused severe misalignment between, for example, product structures and business processes which operate on these structures.

- Detached product structures: In the traditional foundation, the product structure was developed for the onein-all company situation, and the focus was on the development and production of the product. This structure cannot easily be adapted to the needs of the marketing and service functions which leads to local structuring initiatives in areas where the need is greatest. For example, the outsourcing of the production and supply function may result in separate and detached product structures which in turn profoundly severs the information flow between these functions.

- Confused coordination: Coordination is usually expressed by process models in which the dependencies between activities impacting the product's life-cycle states are shown. The traditional process models do not clearly distinguish between activities performed in-house and partners outside the company. Moreover, the process models are not aligned with the evolution of the product structure which results in a confusion about how coordination shall be performed.

- Ad-hoc IS architectures: At Ericsson the IS architecture in the traditional foundation consists of a central product IS with local client applications, a so-called Information Resource Management architecture (see for example [33]). The central IS contains mainly product related information which is structured according to the needs of the stable period. In addition to the central IS, a large number of other ISs have emerged to meet various needs. Some examples of these are Product Data Management (PDM) systems, Software Configuration Management (SCM) systems ( [21], [26], [7]), Requirements Management (RM) tools and Enterprise Resource Management (ERP) systems. Many of these systems also contain product related 
information. These systems were introduced largely in an ad-hoc manner which resulted in a considerable overlap in functionality and managed information. This has been observed for PDM and ERP [29], PDM and SCM and PDM and RM [28]. With the arrival of the turbulent period, this fragmentation has accelerated. Projects developing ISs are launched without any coordination of concepts, product structures and processes. This state of affairs makes it difficult or even impossible to modify the IS architecture or even individual ISs.

- Disjointed centralized control: During the stable period, the control of the management foundation could be kept in-house. Central corporate units could decide which standards were to be used and how these should be interpreted. These standards were mainly about the rules for identification and revision control of products and documents as well as with the structuring of the product. The emergence of more independent in-house functions and cooperation with partners erodes the authority of the central control function. Since the traditional standards reflected basically the needs of the development and production functions, it is difficult to develop the standards to meet the needs of functions like marketing and service. The cooperation with partners also brings completely new standards into focus. Thus, the whole issue of control needs to be reconsidered.

When these and other issues are surfacing the natural strategy is to modify the existing foundation. However, since this foundation was established under significantly different circumstances, only marginal improvements can be expected. In fact, most modifications will most likely impair an already confused situation. The main reason is that the traditional foundation lacks theoretical constructs for coping with surging issues like achieving shared meaning among actors, managing interdependencies between product structures, ISs and processes and balancing central control with local autonomy.

\section{Research design}

One point of departure in our study is that product life-cycle management is carried out in a socially organized setting where human actors come together to produce a certain outcome. Thus, in contrast to natural science, which deals with making predictions and finding general laws based on experiments, our study object includes humans. In these situations interpretation, meaning, understanding, context, etc. will play a major role [23]. Consequently, our study may be regarded as an interpretative one [34].

The unit of analysis in our study is the activity domain and its constituents as described in Section 3.1. This means that the study can be classified as a single case, multiple unit of analysis study [38]. The extension of the study is roughly six months during the second half of 2002.

The research method may be classified as action research [1], [3]. Both authors participated participating in the PLM investigation project (see Section 4). They have been working with PLM related problems as employees at Ericsson for many years (one author, Taxén, for more than 30 years). In the action research the ADT was used as a framework for both informing the practice and analyzing the results [3]. Based on the findings the theory is further articulated. Thus, the research objectives are related to the results in a hermeneutic manner via the ADT.

The empirical data consist of internal documents, personal notes and artifacts developed in the investigation project. As participants we had unlimited access to these empirical data. The publication of the results has been agreed with Ericsson and no significant results have been withheld other than company sensitive economical information. Drafts of the paper has been read and commented by the project manager. No interviews have been made since we estimated that this would not provide any significant additional data besides the information we could collect as participants.

\section{PLM apprehended as coordination}

PLM is defined by CIMdata as follows:

"PLM is a strategic business approach that applies a consistent set of business solutions in support of the collaborative creation, management, dissemination, and use of product definition information across the extended enterprise from concept to end of life - integrating people, processes, and information. PLM forms the product information backbone for a company and its extended enterprise." (CIMdata, [4])

As can be seen, a number of elements of various nature are included in this definition. In order for the definition to be useful it must be operationalized, that is, its elements must be expressed in such a way that they can be observed and manipulated in order to influence an industrial practice. Moreover, PLM implementations has 
mainly been geared towards technical aspects such as product structures, processes and ISs. Although certainly valid also in the turbulent situation, we claim that other issues should be in the forefront such as

- the achievement of shared meaning among the actors regarding what constitutes PLM,

- the management of dependencies,

- $\quad$ and the distribution of control.

The achievement of shared meaning may be one of the hardest ones to achieve in organizational change management [18], [31]. The reason for this is that the perceived reality in an organization is a socially constructed reality [24]. By this we mean that the meaning of any relevant phenomena in the organization is a result of social interaction processes among the actors in the organization. The single, most important criterion by which a certain action is judged its usefulness. Is the result of the action purposeful and meaningful in the organization? Does it produce usable results? Etc. For example, a concept like "work package" may be utilized in a development process and implemented in an IS. If this leads to successful outcomes in projects, "work package" will gradually become a reality in the organization as solid as tools, buildings, etc. What the actors hold for true is the truth in that particular organization. This means, for example, that concrete artifacts like a process model constitute the social reality in the organization rather than 'representing' something outside that reality.

It is very unlikely that organizations evolve identical social realities. During the stable period this played a minor role since most organizational functions were performed in-house. However, in the turbulent situation, different meanings of core concepts is becoming increasingly problematic due to the proliferation of company functions, both within the organization and as part of the extended enterprise.

Concerning dependencies the implementation of PLM has primarily been done by concentrating on one of the elements at a time. For example, processes have been in focus for a number of Business Process Reengineering (BPR) initiatives during the 1990s. However, about $50 \%$ to $80 \%$ of these initiatives are believed to have failed [9]. There are some indications that this is in part due to the negligence of the context of the process and its interdependencies to the product structure (ibid., Chapter 14).

The transformation from the one-in-all organization to a network of cooperating organizations implies that the whole issue of control must be reconsidered. No part in the network can maintain a coercive control of the cooperation. Instead, an imperative set of regulatory measures must be mutually agreed upon for the benefit of all parties involved. These measures must be defined in such a way a proper balance is struck between too strict and too loose a control.

In order address these issues we propose to view PLM as a form of coordination. Coordination has been extensively treated in the literature, e.g.[17], [15], [20]. We will start from the definition given by Malone and Crowston [17]: "[Coordination is] the management of dependencies between activities". This corresponds closely to the process element in the PLM definition above. Taxén has suggested to elaborate this definition by regarding coordination as a particular work practice where the outcome is to provide coordination of, for example, a development project [31]. We will follow this route and outline how the PLM elements can be integrated into a coherent whole based on the theory of activity domains given in [31].

\subsection{An integrating framework - the Activity Domain Theory}

The Activity Domain Theory (ADT) was suggested by Taxén as a suitable ontological framework guiding the quest for operative solutions meeting the needs in the turbulent situation [31], [32]. The ADT evolved over more than 10 years in the Ericsson practice. Here, we can only recapitulate the essentials of the theory.

The ADT has its roots in the praxis philosophy which regards praxis as the nexus of human activity. In praxis humans act in the world to change their social and material conditions [14], [12]. From this general conception the construct of the activity domain is derived. The activity domain should be apprehended as a structured form of praxis where actors are working together on an object in order to produce a certain outcome. The actors have a motive for coming together, which is the reason why the activity domain exists. The object is the main driver for organizing the activity domain. These elements of the activity domain are inspired by Activity Theory [5]. Over time, the activity domain evolves into a coherent social construct in which the actors share a common ideology. By ideology we merely understand any wide-ranging systems of beliefs or ways of thought.

In the activity domain the interaction between individuals and their environments is considered to be the basic knowledge generating mechanism. The interaction is mediated by various sign systems of which language is the prime one for humans [11]. The signified phenomena may be natural in origin or part of our social reality, and 
"... any item of nature, technology or consumption can become a sign, acquiring in the process a meaning that goes beyond its given particularity...” ([37], p. 10).

The sign-mediated interaction can be analyzed from a cognitive, conceptual and linguistic perspective. Since these perspectives span fundamental modes of human existence we conjecture that any quality common to several or all of these modes should be important in a theory about human activity. From this analysis a set of activity domain constituents has been proposed [31], [32]. For PLM purposes these constituents can be operationalized as follows:

- A context model which operationalizes the constituents spatial orientation and contextuality. This model signifies the context of the activity domain by articulating relevant phenomena, how they are characterized and how they are related to each other. When this model acquires a shared meaning it enables the actors to orient themselves in the activity domain, rather in the same way a map does. The anatomy in Figure 1 is an example of an instantiation of a context model.. In the literature models designations like 'information model', 'data model', 'business model', etc. can be found. We apprehend these models as different types of context models, thus highlighting their contextual nature.

- A transition model which operationalizes the quality dimension domain transition. This model is an elaboration of the Specification Based Data Model suggested by Gandhi \& Robertsson [8]. The purpose of this model is to express how significance structures in different activity domains interact. Basically, this is a mapping and interpretation operation. For example, the status of a work packages in Figure 1 is determined by the states of a set of internal elements in the work package domain, for example, documents. In this paper we will use the term information architecture to denote the ensemble of the context and transition models. The product structure is included in the information architecture.

- A process model which operationalizes the constituent temporal orientation. This model signifies the dependencies between the activities in the activity domain and thus coordination according to Malone \& Crowston ([17], p. 90).

- A domain core which operationalizes the constituent stabilizing core in the activity domain. The core is made up by articulated elements of the ideology such as norms, routines, rules, standards, etc., and is part of the ideology shared by the actors in the domain.

- Information systems which operationalizes the constituent instrumentality. The models and the domain core are implemented in the ISs, which is used to support the coordinating activities in the activity domain. The ISs constitute in relation to each other the information system architecture in the domain.

- A domain construction strategy which operationalizes the constituent experiential learning. This strategy is utilized to construct the social reality in the activity domain in such a way that shared meaning is achieved. The models and their implementations in the ISs are iteratively reflected over and tried out in practice in the activity domain. In order for this strategy to work, the ISs must be easily modified.

More details about the Framework can be found in [30] and [31]. The operationalized activity domain can be illustrated as in Figure 2: 


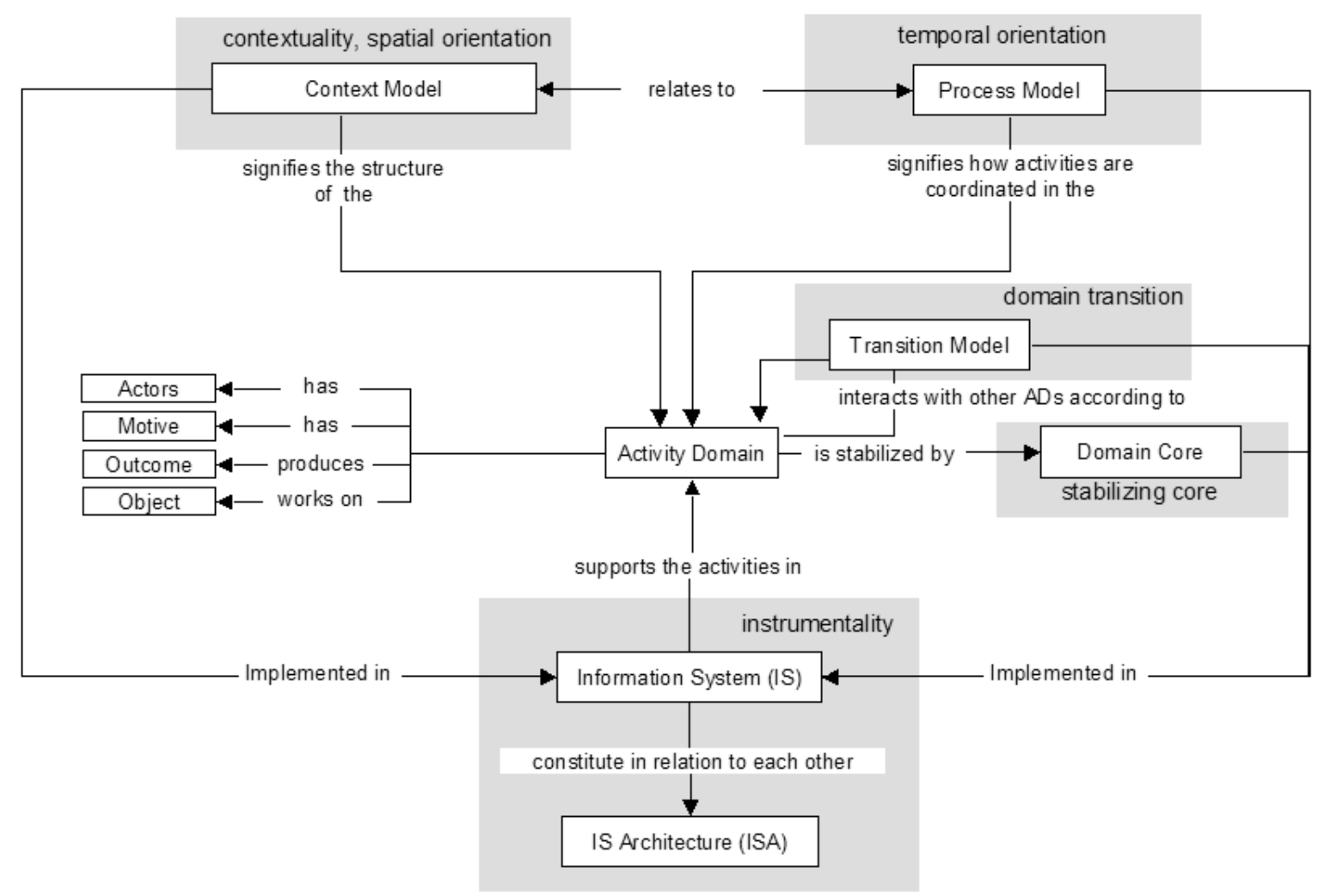

Figure 2. The structure of the activity domain

Taking the activity domain as a basis for the alternative PLM foundation has several advantages. First, it directs the attention to the interdependencies between the elements of the activity domain. The unit of analysis may be taken to be the activity domain as a whole rather than its individual elements. As noted by Virkkunen and Kuutti [36], focusing on separate elements may be insufficient in organizational analysis. Second, the activity domain construct can be recursively applied to any chain of cooperating organizational units, regardless of whether these are in-house or other organizations. Third, since shared meaning is an inherent feature in the ADT, the construction of social reality in the organizations is emphasized. Fourth, since the activity domain is operationalized in terms of information architectures, process models, ISs, etc., the construct aligns nicely with elements which are already significant in most organizations. Thus, the effort in rethinking PLM is confined to the internalization of the activity domain construct in the organizational language, an effort which may be substantial but nevertheless quite obtainable.

The elements in the ADT can be found in other modeling frameworks, such as ARIS [22], UML [6] and the framework for modeling and analyzing Engineering Information Management systems proposed by Svensson et al. [27]. All these frameworks consist of at least models that describe the process, information, organization and information systems aspects. The main purpose of these frameworks is to support a thorough analysis of the existing state of an organization in order to create a solid ground for future developments. Svensson et al. acknowledge the inherent complexity and the difficulties in achieving a shared meaning. They also state that to master the complexity, several views are necessary.

In comparison with the ADT, the other frameworks are mainly focused on technical aspects. They also consider the models as explicit representations of the phenomena studied, rather than being means to build the social reality of the actors. Furthermore, they lack a unifying theoretical perspective of human activity which may guide the selection of elements to be included in the framework. For example, shared meaning, contextuality, experiential learning and stability are not included. Moreover, there is no integrating category comparable to the activity domain. The major difference between the approaches is the emphasis put on shared meaning between the actors.

In summary, we claim that the ADT provides a coherent ontological framework which can be operationalized for implementing an alternative foundation for PLM. In the following section we will report on some results form applying this framework at Ericsson. 


\section{Results}

For some time it has been evident that the traditional product life-cycle management has to be changed at Ericsson. Most of the concerns discussed in the introduction have been experienced. For example, during year 2001 alone a large number of information management initiatives were launched around the company without a common, basic terminology. Another example is an analysis preceding the introduction of a major ERP system. This analysis revealed that more than twenty incompatible product definitions existed in the organization.

In order to lay a alternative foundation for product life-cycle management a project called the PDM Core project was started during 2001. The authors participated in this project, both as employees and researchers. In the next sections, we describe some preliminary results from this project. Each result is followed by a short statement of the effects from using the ADT as a guiding framework for an alternative foundation for PLM.

\subsection{Activity domains at Ericsson}

Activity domains as a concept had not existed before, but they were manifested as associated, albeit detached elements such as business processes, information architectures, ISs, etc. Existing business process were used by the PDM Core project to identify requirements on the alternative foundation. However, these models were activity-based models which only indicated the order of activities performed in various functional units in the organization. Existing analyses of how the activities were related to the product structure were at most superficial. This was regarded as quite insufficient for capturing the full complexity of the life cycle management. Furthermore, the process models were undergoing several changes while the project was running.

Thus, there was a need for a stable way of identifying work units in the company with a similar purpose and which were reasonably invariant to organizational changes or process restructuring. Therefore, it was decided to view the company as set of interacting activity domains. As a result the company was conceived as one main activity domain which coordinates the outcomes of four major activity domains:

- Research and Development (R\&D): The motive of this activity domain is to development products. This is done at product development units worldwide. Each product is sold on many markets, produced by many supply units and serviced by many service units.

- Marketing and Sales: The motive of this activity domain is to market and sell total telecommunication solutions to customers. This is done at market units worldwide. There are many markets, and each market unit works with many products and many supply and service units.

- Supply and Implementation: The motive of this activity domain is to produce and install total solutions at customer sites. This is done by Flow Control Centers worldwide. Each center services many products and markets.

- In Service Support: The motive of this activity domain is to service and upgrade installed solutions at customer sites. This is done by services units worldwide. Each service unit supports many products and is active on many markets.

\section{Effects}

Conceiving the company as a set of interacting activity domains provides a comparatively stable construct which changes less frequently than organizational structures. Thus, activity domains provide a suitable perspective for PLM in which process models, information architectures, ISs, etc. are seen as interrelated elements in a coherent whole.

\subsection{Cleaning up concepts}

When the PDM Core project was started, it was soon realized that the team members had to achieve some shared meaning of key concepts used in the project. Another issue was to improve the communication internally in the organization by having a consistent structure in the description of the concepts. To this end, a set of fundamental categories (FC) for information management was defined in an internal report. The FCs were a subset of the constituents in the ADT. After some initial confusion, it was decided that the results of the PDM Core project would be based on the FCs.

\section{Effects}

Quite soon, an initial cleaning up of the concepts and terminologies flourishing within the area was achieved. Gradually, the FCs were internalized in the team and among actors in the immediate surrounding. As a consequence the categories were constantly refined and evolved during the project. The set of FCs is a means of coping with the conceptual disarray in the company by introducing a coherent terminology based on the ADT. This means that locally defined concepts, which otherwise are confined to isolated parts in the company, now 
can be grounded in fundamental ones which are valid for the entire enterprise. This in turn makes it easier to allow locally defined dialects without losing control of how they are interrelated.

\subsection{Balancing central control with local autonomy}

The diversification has made it impossible for a central organizational unit to dictate in detail how information architectures, business processes, ISs, etc., shall be implemented. This is especially valid for interorganizational cooperations. On the other hand it is not possible to leave to the individual units to structure these elements entirely on their own since that would cause coordination to break down. Thus, a balance between a necessary central control with local autonomy has to be struck. This balance comprises all constituents of the activity domain. For example, in the PDM Core project it was proposed to divide the information architecture in two sets on the enterprise level. The core set contain the object types, relations, etc., which are common for two or more main activity domains. The supplementary set are related to specific activity domains. The core set is relatively stable over time while more flexibility is allowed for the supplementary set.

An example of an information architecture for the Research \& Development activity domain is shown in Figure 3. The grayish entities belong to the core set, while the other entities are specific for the R\&D domain. The object in focus in this domain is the 'DESIGN_PRODUCT' around which the other types are organized. Similar models may be constructed for the other activity domains.

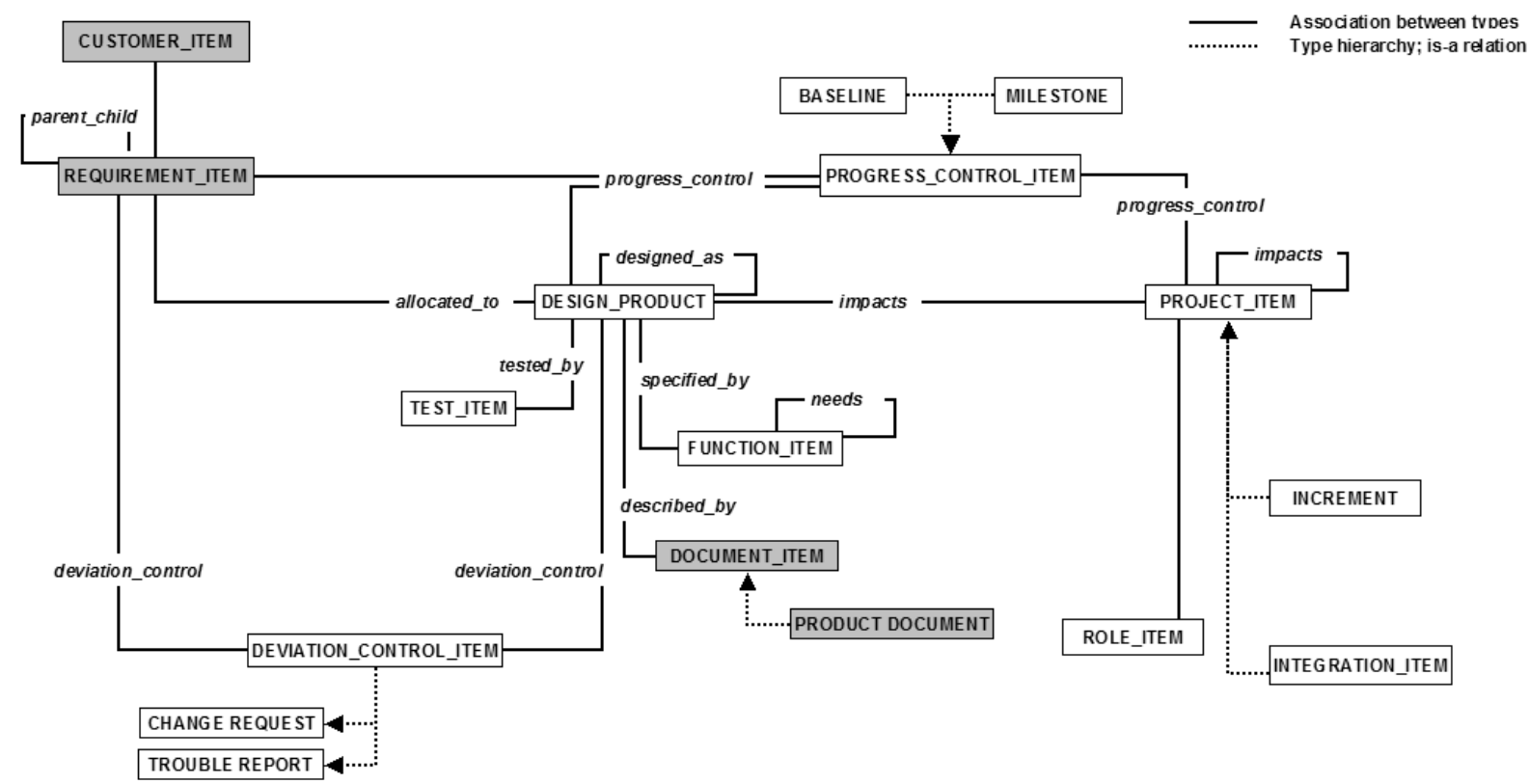

Figure 3. An information architecture with core and supplementary entities.

The core set is common to more than one activity domain which make them central for inter-domain coordination. The supplementary set, on the other hand, is used for coordination in the subordinate activity domains.

\section{Effects}

The identification of core and supplementary categories is an example of how centralized control can be balanced with local autonomy. The responsibility for the information, which is vital to the company, can be assigned to a central authority, thus creating a stable information core. Coordination is made possible without constraining the activity domains in ineffectual ways. A similar approach may be applied to the business processes and the ISs.

\subsection{Domain specific product structures}

The master product structure used at the company is a development oriented structure. It consists of a functional and organizational structuring of the product into subsystems. For each of these, a realization structure is defined, which defines the assemblies or parts building the product. For each part there is an associated set of documents describing various views of the product such as marketing, development, manufacturing, installation, etc. The structure contains various configuration and revision rules which are used, for example, to build configurations for manufacturing and installation purposes. 
Basically, the product is structured from the needs of the Research \& Development activity domain. However, the needs from the other activity domains indicate that a development oriented product structure is not sufficient. Each domain apprehends the product according to its own needs. For example, in the marketing and sales domain the products are conceived and managed from a marketing point of view. The most relevant aspect in this context is how the products are presented to the customer. As a result the entities in the structure need to carry domain-specific attributes and follow domain-specific structures.

Figure 4 shows one proposal of a alternative product structure. The top entity is a product type that carries the properties which are common for all product entities, followed by activity domain specific product entity types. The domain-specific entity types have properties and life-cycles which are unique for each activity domain. These entities can be further specialized according to the needs of each activity domain. Some product entities may appear in different structures with different characteristics emphasized.

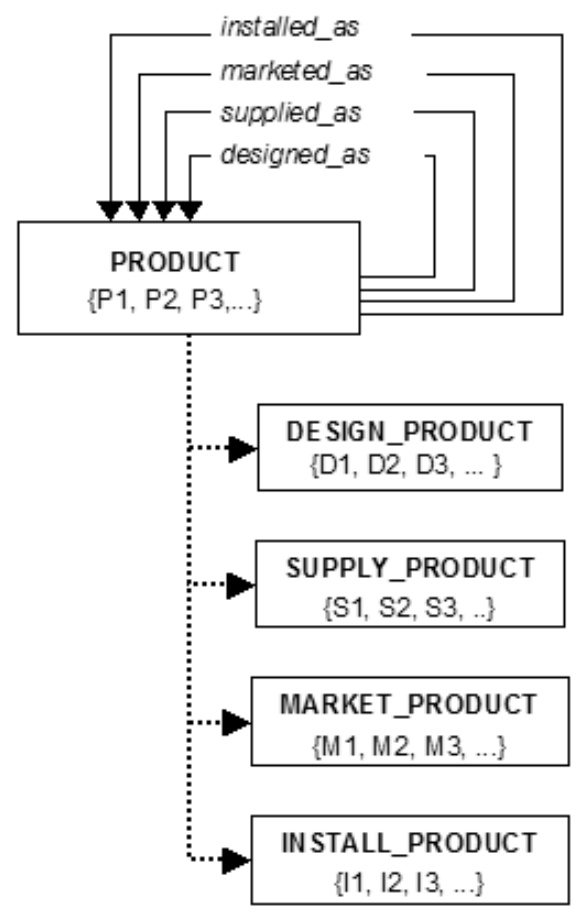

Figure 4. An alternative product structure

The relationships between product entities are also domain-specific. One type of relationship, designed_as, is used to structure product entities in the development domain and so on. The life-cycle states are determined by rules which indicate how a certain state depends on other states. For example, the product state P1 may be set when the states D1 and M1 has been set, indicating that some design and marketing activities have been finished.

\section{Effects}

The domain-specific product structures address the problem of diversified product structures. By allowing such structures, each domain is given a certain freedom to construct an activity domain specific structure according to their needs. This can be done without jeopardizing the need for coordination their work with other domains. In this way a unified management of product structures is possible without hindering diversification.

\subsection{Business process reconstruction}

The business process at Ericsson shows the coordination of activities in the main Ericsson activity domain. This process is traditionally illustrated as in Figure 5. 


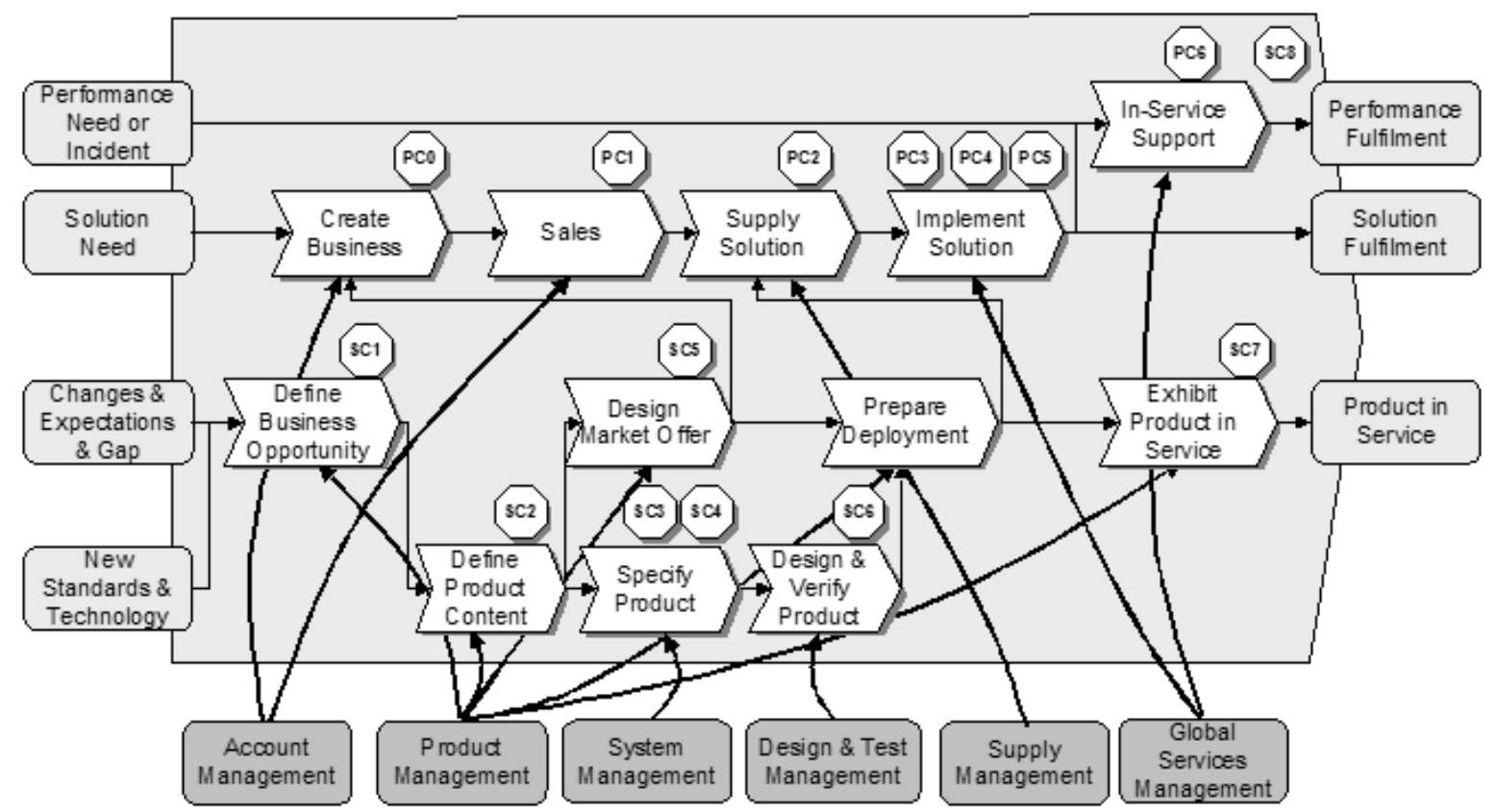

Figure 5. The main Ericsson business process - activity based process model

This process model was defined without the activity domain construct as a basis. Thus, it exhibits the general feature of an activity-based process models of focusing on the dependencies between activities and placing the dependencies between information entities in the background. Certain entities are not even visible in the model. Thus, the dependencies between the process model and the information elements are difficult to apprehend. This means that it is very hard to agree upon how to manage product life-cycles and coordinate activity domain outcomes from this type of process model. Differently put, the relevant signifying properties of the model are weak.

As an alternative to the activity based process models we propose the Information Flow Diagrams (IFD) (see Figure 6).

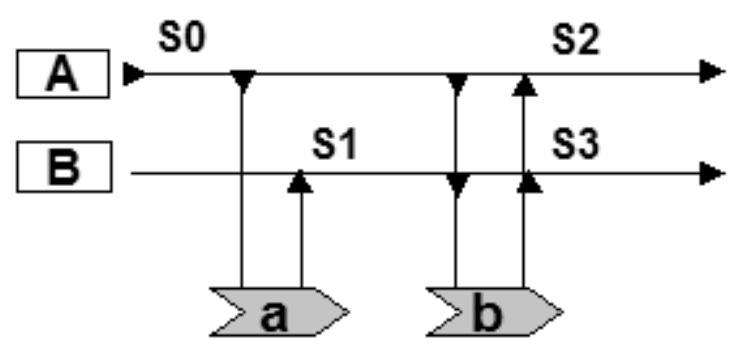

Figure 6. Information Flow Diagram.

An IFD consists of the entities, their life-cycles, the activities, and the dependencies between the entities and activities. The entities are signified by boxes piled up vertically to the left. The life-cycles of the entities are signified by horizontal lines aligned with the entities. At the bottom of the diagram the activities are outlined. The dependencies between the activities and the entity life-cycles are signified by vertical arrows, which indicate which entities are prerequisites for an activity and which status changes result from the activity.

The IFDs belong to a class of process models called entity-based process models in which the process is controlled and monitored through the progress of the entity states [10]. Thus, the entities are in focus rather than the activities. The origin of the IFDs is obscure, but they were frequently used at Ericsson in the 1990s. The IFDs have several appealing qualities. First, the state progress of an entity is easy to follow, which is important for life-cycle management. Second, the entity states provide a more stable control mechanism than the activity states in the turbulent situation. Third, the dependencies between information elements and activities are easier to apprehend with IFDs. Thus, in the turbulent situation, the signifying properties of IFDs are superior to the activity based models once the basic nomenclature has been learned. This in turn will make the achievement of shared meaning concerning the processes easier. 
The business process was reconstructed using the IFD process model (Figure 7).

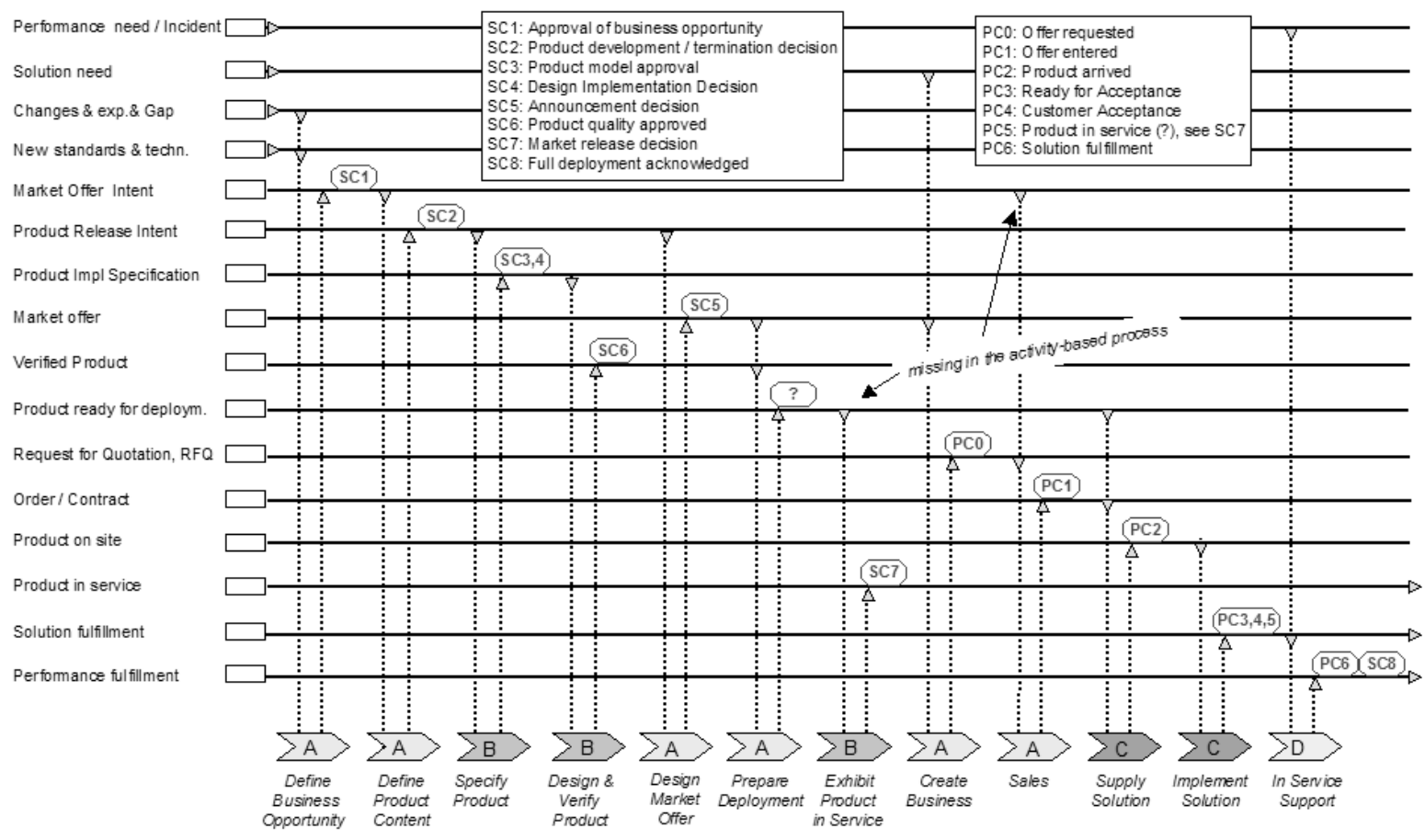

Figure 7. The main Ericsson business process - IFD based process model. A: Market \& Sales. B: Research \& Development. C: Supply \& Implementation. D: In Service Support

The IFD based process model provides a better balance between the activities and the information entities impacted by the activities. Also, it clearly shows the state progression of the information entities, which make the model more suitable for defining the life-cycle of the product and coordinating the activity domains. The analysis showed that the activity-based process model was inconsistent with the product structure regarding naming conventions and state coupling. For example, there was no connection between the state 'SC6' (product quality approved) and life cycle states of the product as defined in the product structure. The reason for this omission is probably that the state definitions in the main business process were specified from the needs of the main Ericsson activity domain without considering the coupling to the other activity domains. Thus, this can be attributed to the lack of overview of how the different activity domains interact.

Furthermore, it can be noted that the product appears in several 'threads', each of which signifies a different state of the product. These threads can be combined into one thread which will then show all states for the product during its life-cycle. Thus, the process model can be further compacted. Finally, the model shows which activity domain executes which activity. This provides an opportunity to analyze the allocation of the responsibilities for the activities indicated in Figure 5. As a rule, a certain responsibility should be allocated to the same activity domain. This is not consistent in the Ericsson business process. For example, 'Product Management' is found in both the Market \& Sales and Research \& Development activity domains.

Effects

The usage of IFD diagrams provides a better control of the coordination of the outcomes of different activity domains than traditional activity-based process models. The coordination relies upon the dependence between the entities in the product structures and the activities in the process. These dependencies are expressed in the IFD. Furthermore, existing business processes can be analyzed and reconstructed in a more precise way using IFDs.

\subsection{The Core Catalogue}

A key component in achieving a balance between central control and local autonomy is the Core Catalogue, see Figure 8. The Core Catalogue is a central IS which interacts with activity domain-specific ISs. The Core Catalogue contains core data collected from all main activity domains. Only those objects, attributes and relationships classified as core ones are stored in the Core Catalogue. 


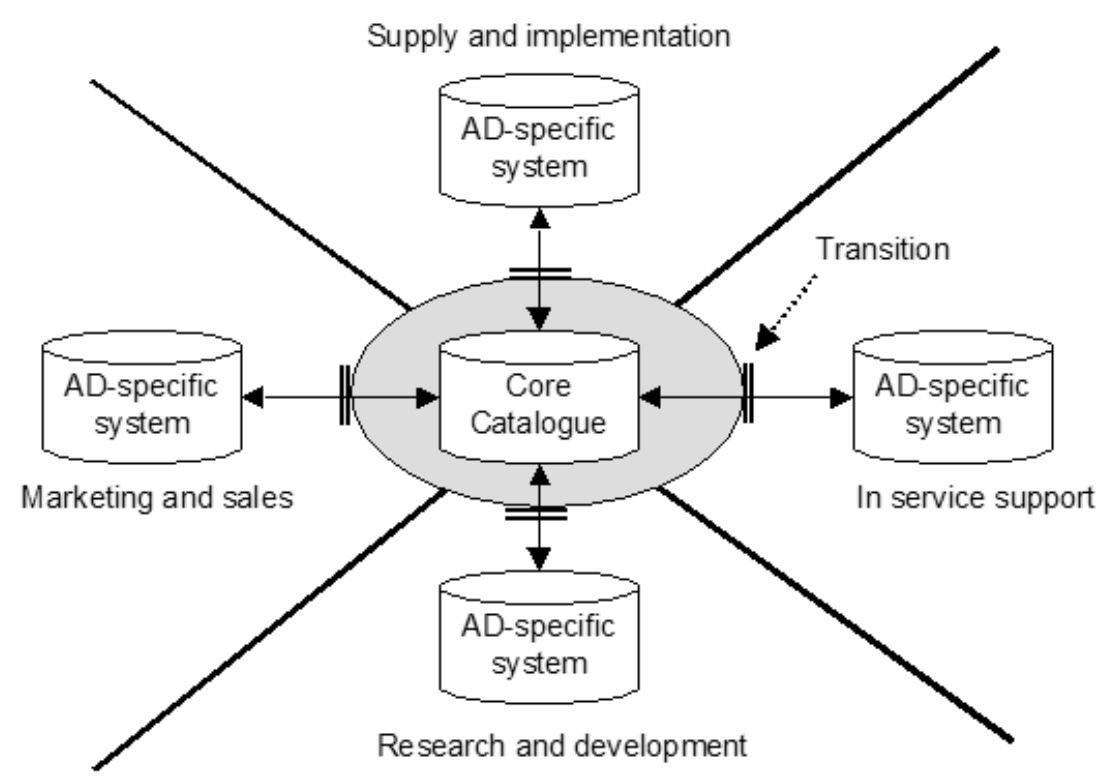

Figure 8. The Core Catalogue concept

The catalogue manifests the domain core in a company from an IS perspective. It enables a controlled communication of data between the activity domains. In doing so it may be necessary to map the information elements from these domains to the catalogue. How this is done is modeled by the transition model. One example of such a mapping is that the concept of "material" in the ERP system used in the Supply and Implementation domain is mapped to the "product" concept in the Core Catalogue.

A central idea in this concept is that the different activity domain shall be in control of the activity domain specific ISs. The construction of the social reality implemented in these systems is best done by the actors in the domains. Of course, company wide rules for these systems can be specified in the main domain core, such as, for example, that the ISs should use the same IT-platform.

The Core Catalogue also provides a means to restructure the IS architecture in the organization. Some ISs used in the activity domains have acquired the status of 'immutable mobile' or 'black boxes' in the terminology of Actor Network Theory [16]. This means that the ISs and their uses are firmly established among the actors. Although it would technically be possible to replace the ISs, it cannot be done without creating resistance and severe conflicts as long as the ISs are embedded in an existing activity domain. The Core Catalogue makes it possible to manage these conflicts by providing a structured exchange of core data between different ISs while they are in active use. If it is decided to phase out a certain IS, this can be done in a systematic way.

\section{Effects}

The Core Catalogue is a central mechanism for coordinating the activity domains. It also provides a means to balance centralized control with local authority. Furthermore, by introducing a Core Catalogue it is possible to address the problem of ad-hoc IS architectures.

\section{Discussion}

As can be seen from the results, the use of the ADT as a guiding framework brings to the surface a number of issues which would otherwise have remained in oblivion. Analytical and constructive efforts can be focused on the interplay between information architectures, processes and ISs rather that on these elements in isolation. This is an absolute necessity in any alternative foundation for PLM today. Moreover, activity domains provide a unified way of apprehending the coordination of both interorganizational and intraorganizational activities. The elements of an activity domain are the same regardless of whether the activity domains are confined to one and the same organization or in different organizations. As pointed out, this provides a more stable unit of analysis than focusing on the organizational structure. This is especially important in the agile period of today with frequent out-sourcings, mergers and acquisitions. 
Furthermore, the notion of activity domains takes into consideration individual and social aspects of PLM, especially the issues of signification and shared meaning. Since the perceived reality in organizations is regarded as a constructed social reality, we claim that these issues are of outmost importance and in fact more difficult to tackle than technological issues [30]. This is in line with recent research in IS development which regards ISs as social systems (see, for example, [13]or [35]).

With the introduction of the ADT a new social reality was gradually established in a small but influential group of actors at Ericsson. The construct of activity domains achieved significance in a small circle of actors as a practical way of reasoning. This provided a 'bridgehead' for further diffusion of this reality into a larger set of actors. However, there is no guarantee that this will prevail. The future diffusion of this foundation may be hindered by the current restructuring of the company, leading to a relapse into traditional thinking.

The new product structure classification is currently a proposal which must be further detailed and verified in practical applications. Most certainly the current proposal will be modified. However, the general principle of several product structures aligned to the needs of the activity domains appears to have been accepted. This provides an 'unlocking' effect on the hitherto fruitless attempts to come up with one product structure for the entire organization. This in turn makes the effort to achieve a shared meaning about this structure substantially less since the commonality can be limited to the bordering entities in the structures. The price that has to be paid is that the different product structures have to be translated into each other when necessary. A similar proposal has been suggested by Brown [2].

The IFD diagrams were used as an analysis tool in the PDM Core project group. Since inconsistencies were found in the existing business process, there are strong arguments for complementing the traditional process models with IFD models. However, the further usage and diffusion of IFDs in the organization is dependent on the adoption of the these by actors responsible for the development of the business processes. This was not secured at the time of PDM Core project.

Concerning the Core Catalogue concept, prototyping was started during the study and a first implementation of the concept was done. However, the classification of the information architecture into core and supplementary sets, which is crucial for the catalogue concept, was not consolidated. In this study we also did not address the question of what particular ISs are suitable as the Core Catalogue IS or the activity domain specific ISs. A general observation is that the activity domain specific ISs are more exposed to changes than the Core Catalogue IS and thus must be easy to modify. In order to solve these issues, a long term and thorough effort has to be initiated. The upheaval in the organization during the study makes it unlikely that such an effort would be launched in the near future.

In the PDM Core project group there was a clear insight that there must be a balance between mandatory, enterprise wide imperative aspects of the activity domains and such aspects that can best be handled locally by each individual domain. This is also in line with other research (see, for example, [25]). In the study, only the information architecture was investigated more closely from this aspect.

However, the insight about the balancing issue was not widespread during the study. Rather, strong centralistic tendencies became more expressed as a result of the cost reduction hunt in the company. There was a great pressure to streamline PLM activities under the banner of "one process is good enough". The likely outcome of this tendency is that calls for more sophisticated solutions will be sparse.

The action research aspect of the project has been to provide the theoretical perspective of the ADT as a frame for structuring the results and emphasize some aspects which would otherwise have been neglected. This had a substantial influence of the reasoning and concept construction in the project group.

Another factor influencing the validity of the results is the approach adopted by those involved in the project. The project was staffed by a mix of IS consultants, IS developers, IS generalists and information modelers. Some of them had operational experience from the company while the remainder had been working with ISs and information management related to the operational activities of the company. The perspective of the participants in the project was largely biased against ISs, information modeling and to some extent process modeling. A consequence of this was a tendency towards the end of the study to focus on traditional IS implementation matters rather than on long term architectural issues.

The results obtained in this study have been derived from a single project, which means that the transferability of the results to other, similar application areas needs to be further investigated. The kind of result derived is on a 
high conceptual level and affects the company as a whole, which ensures that the results are not dependent on local variations within the company. We argue that the set of problems presented are valid for many types of manufacturing industries such as electronics, the automotive industry and others. Some evidence for this has been found in studies at an automotive company [29] and studies at electronics firms [21].

Given the nature of the study and the results achieved, an obvious continuation of the study would be to apply the suggested theoretical perspective in another company setting. The objectives would be to validate the transferability of the ADT and resolve open issues before a full scale implementation of the foundation is launched. Some specific research questions are:

- Which is the application scope of the theory? In what kind of organizations can the theory and its operationalization influence the practice?

- What are the implications of the theory on the IS architecture in the organization? What properties should the Core Catalogue and the activity domain specific ISs have? For example, it is likely that the activity domain ISs must be changed more frequently than the Core Catalogue. For a discussion of these matters, see [31].

- How shall activity domains be identified? Are there criteria which can be used to this end?

- How shall domain cores be defined to provide an optimal balance between imperative rules and autonomy between cooperating activity domains?

\section{Conclusion}

The ability of the Activity Domain Theory to serve as a theoretical perspective for an alternative foundation for managing product life-cycles has been investigated. Concrete operational results have been achieved at Ericsson. The results suggest that the proposed alternative foundation for PLM has a potential to meet the needs emanating from the diversification of organizational functions, increased complexity and an increased rate of change. Moreover, the Activity Domain Theory provides an integrating perspective of social, individual and technical aspects. Thus, it complies well with the call issued by Martinsons \& Davidson [19] for a more unified and complete understanding of various phenomena associated with management. However, the result were confined to a small group of actors at Ericsson. At the time of conclusion of the study the further diffusion of foundation to the entire company was not secured. Moreover, a number of issues need to be further investigated. Thus, the validity and transferability of the alternative foundation on a large scale has not been confirmed so far.

In conclusion however, the results are still preliminary, but promising. We claim that the alternative foundation presented in this paper is an important step towards improved product life-cycle management in the turbulent situation of today.

\section{References}

[1] Baskerville R, Wood-Harper T (1996) A Critical Perspective on Action Research as a Method for Information Systems Research, Journal of Information Technology 11,1996, pp. 235-246.

[2] Brown D H (2001) Fundamentals of shared product structure, D. H. Brown Associates, Inc., Port Chester, New York, USA.

[3] Checkland P (1991) From Framework through Experience to Learning: the essential nature of Action Research, in Information Systems Research, Contemporary Approaches and Emergent Traditions, Nissen, H.E. \& Hirschhem (Editors), pp. 397 - 403.

[4] CIMdata (2003) What is PLM?, http://www.cimdata.com/PLM_index.htm, August, 2003.

[5] Engeström Y (1999) Activity theory and individual and social transformation, in Engeström Y, Miettinen R, Punamäki RL (editors) Perspectives on Activity Theory, Cambridge UK: Cambridge University Press.

[6] Eriksson H E, Penker M (2000) Business Modeling with UML - Business Patterns at Work, John Wiley \& Sons, Inc., New York, NY, USA.

[7] Estublier J, Favre J-M, Morat P, (1998) Toward SCM/PDM Integration?, System Configuration Management, SCM-8, Lecture Notes in Computer Science 1439, Springer, pp. 75-94. 
[8] Gandhi M, Robertson E L (1992) A Specification-based Data Model, Indiana University Computer Science Department Technical Report TR344, Indiana University, Indiana. Available at http://www.cs.indiana.edu/ftp/techreports/index.html (Oct 2002).

[9] Hammer M, Champy (1993) Reengineering the Corporation: A Manifesto for Business Revolution, New York: Harper Business.

[10] Humphrey W S, Kellner M I (1989), Software Process Modeling: Principles of Entity Process Models, CMU/SEI-89-TR-2, Software Engineering Institute, Carnegie Mellon University, Pittsburgh, PA, USA.

[11] Innis R (1985) Semiotics. An Introductionary Anthology (edited by Innis R), Indiana University Press, Bloomington, USA.

[12] Israel J (1979) The language of dialectics and the dialectics of language, New York: Humanities P.

[13] Iivari I, Lyytinen K (1998) Research on Information Systems Development in Scandinavia - Unity in Plurality, Scandinavian Journal of Information Systems, 1998,10 (1\&2):135-186

[14] Kosík K (1976) Dialectics of the concrete, Reidel, Dordrecht, The Netherlands.

[15]Larsson R (1990): Coordination of Action in Mergers and Acquisitions - Interpretative and Systems Approaches towards Synergy, Dissertation No. 10, Lund Studies in Economics and Management, The Institute of Economic Research, Lund University Press.

[16] Latour B (1986) The powers of association. In Law, J. (editor). Power, action and belief. A new sociology of knowledge? London: Routledge, pp. 264-280.

[17] Malone T, Crowston K (1994): The Interdisciplinary Study of Coordination, ACM Computing Services, Vol. 26, no 1, pp. 87-119.

[18] March J G, Simon H A (1958) Organizations, second edition, Blackwell Publishers, Cambridge, Massachusetts, USA.

[19] Martinsons M G, Davidson R (2003) Cultural Issues and IT Management: Looking Ahead, Guest Editorial, IEEE Transactions on Engineering Management, Vol. 50, No. 1, February 2003.

[20] Melin U (2002): Koordination och informationssystem i företag och nätverk, Linköping Studies in Information Science, Dissertation No. 6, Institutionen för datavetenskap, Linköpings universitet (in Swedish).

[21] Persson Dahlqvist A, Asklund U, Crnkovic I, Svensson D, Ranby J, Hedin A, Larsson M (2001) Product Data Management and Software Configuration Management: Similarities and Differences, Technical Report, The Association of Swedish Engineering Industries, ISSN 1493-6444.

[22] Scheer D S (2002) IDS Scheer AG - Business Process Excellence, www.ids-scheer.de, December 20, 2002.

[23] Schütz A (2002/1962) Den sociala världens fenomenologi, Göteborg: Daidalaos, 2002 (in Swedish). English original: Common-sense and scientific interpretation of human action, in Alfred Schütz (1962) Collected papers I, Martinus Nijhoff, Haag.

[24] Searle J R (1995) The construction of social reality, London: Allen Lane

[25] Seo M, Creed W (2002) Institutional Contradictions, Praxis and Institutional Change; a Dialectical Perspective, Academy of Management Review, vol. 27, no. 2, pp. 222-247.

[26] Svensson D, Crnkovic I (2002) Information Management for Multi-Technology Products, Proceedings of Design 2002, Dubrovnik, Croatia, 14-17 May 2002.

[27] Svensson D, Malmström J, Pikosz P, Malmqvist J (1999): A Framework for Modeling and Analysis of Engineering Information Management Systems, Proceedings of the 1999 ASME Design Engineering Technical Conferences, September 12-15,1999, Las Vegas, Nevada, USA.

[28] Svensson D, Malmqvist J (2001) Integration of Requirement Management and Product Data Management Systems, Proceedings of DETC'01, Paper No. DETC2001/CIE-21246, Pittsburgh, Pennsylvania, USA.

[29] Svensson D, Malmqvist J (2002) Strategies for Product Structure Management at Manufacturing Firms, Journal of Computers in Science and Engineering, Vol. 2, Issue 1, pp. 50-58.

[30] Taxén L (2002) An Interaction-based Approach for Structuring Coordination Activities, the First IEEE International Conference on Cognitive Informatics, Calgary, Canada, August 19-20, 2002. 
[31] Taxén L (2003) A Framework for the Coordination of Complex Systems’ Development. Dissertation No. 800. Linköping University, Dep. of Computer \&Information Science, 2003. Downloadable from http://www.ep.liu.se/diss/science technology/08/00/index.html

[32] Taxén L (2004) Articulating Coordination of Human Activity - the Activity Domain Theory, Proceedings of International workshop on Action in Language, Organisations and Information Systems (ALOIS-2004), Linköping University.

[33] Trauth E M (1989) The Evolution of Information Resource Management, Information \& Management 16, pp. 257-268.

[34] Walsham G (1995) Interpretative case studies in IS research: nature and method, European Journal of Information Systems, No. 4, Operational Research Society, Great Britain, pp. 74-81.

[35] Verrijn-Stuart A A (2001), FRISCO - A framework of information system concepts - The Revised FRISCO Report (Draft January 2001), IFIP WG 8.1 Task group FRISCO http://www.wi.leidenuniv.nl/ verrynst/frisco.html

[36] Virkkunen J, Kuutti K (2000) Understanding organizational learning by focusing on "activity systems", Accounting, Management and Information Technologies, Vol. 10, Issue 4, pp. 291-319.

[37] Vološinov V N (1986/1929) Marxism and the Language of Philosophy, Harvard University Press, London. Appeared first in V.N. Vološinov, Marksizm i filosofija jazyka: osnovnye problemy sociologiceskogo metoda v nauke o jazyke, Leningrad 1929.

[38] Yin R K (1989) Case study research. Design and methods, London: Sage. 